approval for screening random schizophrenics for mutations was granted by Lothian Area Health Authority before the initiation of this study.

DAVID ST CLAIR MRC Human Genetics Unit, Western General Hospital, Crewe Road,
Edinburgh EH4 $2 \mathrm{XU}, \mathrm{UK}$.

1 Caine ED, Shoulson T. Psychiatric syndrome in Huntington's disease. Am $\mathcal{F}$ Psychiatry 1983; 140:728-33.

2 Seeman P, Niznik HB, Guan HC, et al. Link between D1 and D2 dopamine receptor is reduced in schizophrenia and Huntington's disease brain. Proc Natl Acad Sci USA 1989; 86:10156-60

3 MacDonald ME, Ambrose CM, Duyao MP, et al. A novel gene containing a trinucleotide repeat that is expanded and unstable on Huntington's disease chromosomes. Cell 1993; 72:971-83.

4 Read AP. Huntington's disease: testing the test. Nature Genet 1993;4:329-30.

5 Warner JP, Barron LH, Brock DJH. A new polymerase chain reaction (PCR) assay for polymerase chain reaction (PCR) assay for
the trinucleotide repeat that is unstable and the trinucleotide repeat that is unstable and somes. Mol Cell Probes 1993;7:235-9.

6 Barron LH, Warner JP, Porteous M, et al. A Barron LH, Warner JP, Porteous M, et al. A
study of the Huntington's disease associated trinucleotide repeat in the Scottish population. f Med Genet 1993;30:1003-7.

7 Spitzer RH, Endicott J, Robins E. Research diagnostic criteria for a selected group of functional disorders. 3rd ed. New York: New York State Psychiatric Institution, Biometrics Res Div, 1987.

\section{Further family with autosomal dominant patent ductus arteriosus}

Occasionally, families have been reported with apparent autosomal dominant inheritance of a patent ductus arteriosus (PDA), although the condition usually appears to be sporadic. ${ }^{1-6}$ We report a further family with eight affected members in two generations.

The pedigree is shown in the figure. The grandfather (I-1) died suddenly after a tooth extraction at the age of 40 ; his wife died of old age. II 1 was diagnosed and operated upon for a PDA at the age of 35 years. Despite having a sister with a PDA and two children requiring PDA ligations, it was not until she brought her third affected child into hospital that she herself was examined. Mild right ventricular hypertrophy was found and a small PDA was closed. She also had coeliac disease. II 2 has been in good health all his life. Because of the family history of patent ductus arteriosus he sought a cardiology opinion at the age of 54 years. A PDA was found with moderate biventricular dilatation and he was operated on successfully. II 4 had been a sickly child throughout her life but became progressively less well in her teenage years. At the age of 18 years bacterial endocarditis and a PDA were diagnosed. Both were eventually successfully treated. In later life she developed myasthenia gravis, scleroderma, and Reynaud's phenomenon. III- 2 was referred to a cardiologist at the age of 7 years with an asymptomatic murmur. After two years of follow up, ventriculomegaly began to develop and the PDA was ligated. III 44 was diagnosed as having a PDA at the age of 5 years, had always been mildly exercise restricted, had ventriculomegaly, and was operated on at 6 years. III. 5 was found to have an asymptomatic murmur at the age of 6 years and her PDA was tied at $6 \frac{1}{2}$ years. She also had coeliac disease. III. 6 had frequent upper respiratory tract infections as a young child and was exercise restricted. At the age of 4 years he was referred to a cardiologist who found a typical PDA murmur. $\mathrm{He}$ was operated on at the age of $4 \frac{1}{2}$ years. His karyotype is normal. III 17 was referred to a cardiologist at the age of 3 years for an asymptomatic murmur. A PDA was diagnosed and ligated forthwith.

Family members are of normal appearance and intelligence and have no symptoms suggestive of a prostaglandin metabolic defect, such as atopy or difficulties during labour. Although all occurrences of PDA have been inherited from an affected mother in this family, paternal-offspring transmission has been described previously. ${ }^{1346}$ The PDAs found in this family were not unusual in their position and varied greatly in the symptomatology they caused.

The empirical recurrence risk for a PDA is $3 \%$ whether it is a parent or a sib that is affected. ${ }^{7}$ Most cases are thought to be the result of polygenic/multifactorial inheritance. In families such as this, where so many members are affected, autosomal dominant inheritance seems likely and the recurrence risk is probably $50 \%$. In order to give realistic recurrence risks to a family where a child has a PDA, the facial phenotype described by Davidson ${ }^{6}$ should be sought, and both parent's cardiovascular systems should be examined. Referral to a cardiologist of any children born to a family with possible auto- somal dominant PDA seems sensible whether or not they have a detectable murmur. LESLIE I SHEFFIELD

The Murdoch Institute, Royal Children's Hospital, Flemington Road, Parkville, Victoria 3052, Australia.

1 Burman D. Family patent ductus arteriosus. $B$ Heart f 1961;23:603-4.

2 Goodyear JE. Persistent truncus arteriosus in two siblings. $\mathrm{Br}$ Heart $\mathcal{f}$ 1961;23:194-6.

3 Lynch HT, Grissom RL, Magnuson CR, Krus A. Patent ductus arteriosus. $\mathfrak{f} A M A 1965 ; 194$ : $135-8$

4 Martin RP, Banner NR, Radley-Smith R. Familial persistent ductus arteriosus. Arch Dis Child 1986;61:906-7.

5 Rogers JC, Begleiter ML, Harris DJ. Paten ductus arteriosus in four generations of a famductus arteriosus in four genera

6 Davidson HR. A large family with patent ductus arteriosus and unusual face. 7 Med Genet 1992 ; 30:503-5.

7 Nora JJ, Nora AH. Update on counselling the family with a first degree relative with a congenital heart defect. Am $\mathcal{F}$ Med Genet 1988;29. 137-42.

\section{Molecular basis of the common electrophoretic polymorphism (Fu1/Fu2) in human $\alpha$-L-fucosidase}

$\alpha$-L-fucosidase (EC.3.2.1.51) is a lysosomal hydrolase involved in the catabolism of fucose-containing glycolipids and glycoproteins. A deficiency of this enzyme leads to the lysosomal storage disease, fucosidosis. ${ }^{12}$ $\alpha$-L-fucosidase exists as multiple molecular forms, which can be separated by various procedures. ${ }^{34}$ The precise molecular basis of this heterogeneity is not understood but it is probably post-translational. All the forms are encoded by a single locus on the short arm of chromosome 1 at $1 \mathrm{p} 34.1-1 \mathrm{p} 36.1$ which encodes the structural gene for the enzyme, FUCA1 ${ }^{56}$ The enzyme shows a genetically determined, common, electrophoretic polymorphism (Fu1/Fu2), which can be detected in blood and tissues ${ }^{7}$ and maps to the structural gene locus (FUCA1) ${ }^{8}$ The minor allele, $\mathrm{Fu} 2$, produces more cathodal forms of the enzyme.

The structural gene for $\alpha$-L-fucosidase has been isolated and sequenced. ${ }^{910}$ It is $23 \mathrm{~kb}$ in length and has eight exons. Two common RFLPs obtained with PvuII and BgII are in almost complete linkage disequilibrium and can be used to haplotype subjects. ${ }^{11}$ Several disease-causing mutations have been identified in patients with fucosidosis. ${ }^{212-14}$ In addition, an $A$ to $G$ transition in exon 5 causing substitution of an arginine for glutamine, Q281R, has been found homozygously in both patients and controls, indicating it is a polymorphism rather than a disease-causing mutation. ${ }^{14}$ All homozygotes for this substitution showed the RFLP PvuII- $B g I$ haplotype, 2-2, 2-2. It was postulated that Q281R might be the molecular basis of the Fu1/Fu2 electrophoretic polymorphism. ${ }^{14}$ Evidence to support that suggestion is presented in this paper.

The Q281R polymorphism creates a new site for the restriction enzymes DsaI and Bsaf1 in exon 5 . It can be readily detected by amplifying exon 5 with the two primers used for mutation analysis (F42 and F43 in reference 14), followed by digestion with DsaI or BsafI (fig 1). Analysis of the Bsafl digestion products by electrophoresis in 3\% agarose (BRL)/ 